\title{
AC 2009-84: NEW DEVELOPMENTS IN ENGINEERING FOR NONENGINEERS
}

John Krupczak, Hope College 


\title{
New Developments in Engineering for Non-Engineers: Functional Analysis as a Framework for Understanding Technology
}

\begin{abstract}
The National Academy of Engineering recently published: "Changing the Conversation: Messages for Improving Public Understanding of Engineering." The NAE states that capable and confident participants in our technologically dependent society must know something about engineering. However the means by which engineers can explain engineering to non-engineers are not well established. In this work the method of functional analysis or functional decomposition is suggested as a framework for explaining technical products and systems. Functional analysis is often used in engineering product design and systems engineering. The major engineering disciplines each employ a form of functional thinking in the development of particular classes or domains of technological products. Functional analysis, or functional thinking is therefore identified as a characteristic of engineering. Functional analysis offers advantages cited as desirable in explaining engineering to a non-engineering audience. A major advantage is that functional analysis does not require extensive prerequisite background knowledge and is readily accessible to the general student. Other advantages include the ability to incorporate a systems perspective, inclusion of underlying science principles used in technology, a natural connection to the engineering design process, and ability to describe a wide-variety of different types of technological devices and systems.
\end{abstract}

\section{Introduction}

The National Academy of Engineering (NAE) recently published: "Changing the Conversation: Messages for Improving Public Understanding of Engineering ${ }^{1 "}$. In this work, the NAE states that capable and confident participants in our technologically-dependent society must know something about engineering. A 2002 report by the NAE entitled, Technically Speaking: Why All Americans Need to Know More about Technology, describes the importance of being literate about technology in the $21^{\text {st }}$ century ${ }^{2}$. In their 2006 report, Tech Tally ${ }^{3}$, the NAE defined technological literacy as "an understanding of technology at a level that enables effective functioning in a modern technological society."

Technology in this context is associated with the outcomes and products of the various engineering disciplines. Both NAE reports emphasize that technology, in a broad sense, is any modification of the natural world made to fulfill human needs and wants. This includes not only its tangible products, but also the knowledge and processes necessary to create and operate those products. The infrastructure used for the design, manufacture, operation, and repair of technological artifacts is also considered part of technology.

It is important for non-engineers to have an understanding of engineering and the technology that is developed by engineers. By implication then, engineers are responsible for making an effort to inform and educate the non-engineering public on technological topics. However, the specific steps engineers should take, and the means that engineers should use to communicate technical 
information to a non-engineering audience are not well-established. This paper suggests a means from within the engineering disciplines that can serve as a framework for describing technology to a non-engineers.

\section{Problem Statement}

The engineering disciplines do not have a well-developed formal approach or a consistent framework to describe technological devices and systems in general terms. Engineers have created the vast variety of human-made products that are essential to our modern lifestyle and way of life. The various engineering disciplines such as civil, chemical, electrical, and mechanical engineering have developed specialized analysis methods and techniques for the design and production of the technology that has transformed the conditions of our existence. The various engineering disciplines operate with a common perspective on technology; however, this perspective to date has been primarily implied rather than explicit. Discerning this uniquely engineering perspective on technology, making the implicit perspectives explicit, elaborating on this perspective and making it part of the way engineers view their actions is an important step in the on-going evolution of the engineering body of knowledge.

At the same time as it is important to clarify the common ground of the various engineering disciplines, there is also a need to be able to explain the technological world in which we live to a general audience. This means of explanation should describe technology from a perspective that is unique to engineering. Engineers need to articulate their unique perspective on technology and utilize it when explaining technology to the general public. The key themes that identify engineering as engineering and define the engineering world view should be readily accessible to interested non-engineers, if, like any other field, the nuances of intricate analysis remain remote. Engineers of all types should be able to use these key themes or perspectives as a tool to explain technology, to the non-engineering public.

\section{Background: Describing Engineering and Technology to a General Audience.}

Some materials already exist to explain engineering and technology to a general audience. Three major approaches are common. One approach focuses on underlying scientific principles utilized in a particular technological device or component. A second genre of materials looks at technology and aims to explain how it works using general terms, graphics, images and visual aids. A third approach directs attention to the engineering design process as a key to describing engineering and technology to a general audience.

\section{Science Principles of Modern Technology}

It is possible for the general audience to learn about engineering and technology from science writing that address the underlying science of particular technologies. A number of textbooks and courses have been developed that are intended for the non-technical audience and are centered on understanding technology. Science is fundamentally an effort to understand the natural world. However, it is becoming more common in the physical sciences to utilize examples from technology or the human-made world to illustrate basics principles of science. Bloomfield has developed a physics course and textbook entitled: How Things Work: The Physics of Everyday Life ${ }^{4}$. Others include Dudley and Bold's, “Top-Down Physics", Watson's 
"Silicon, Circuits, and the Digital Revolution" courses ${ }^{6}$. These physics courses use the humanbuilt world as illustrative examples of principles of physics or focus on a particular subset of technology and describe the scientific principles that underlying its operation. Other physics books intended for the non-science major such as works by Wilson ${ }^{7}$, Trefil and Hazen ${ }^{8}$, and Hewitt ${ }^{9}$, draw heavily on examples from technology.

These works have several strengths in providing an avenue for developing an understanding of modern technology. One strength of this approach is that most do not assume extensive prior knowledge of physics. Explanations begin with first principles. Directed primarily at an audience of non-science students fulfilling science course requirements, they do not rely heavily upon mathematical explanations or arguments but rather emphasize verbal and visual explanations and descriptions of relevant physical principles. Mathematics is used to express relationships and quantitative applications but calculus-based derivations are avoided. For teaching to be effective it must be set in the context of the students' prior knowledge of the subject ${ }^{10}$. Using familiar technology as the setting for explaining a particular scientific principle effectively brings in students' prior knowledge through their experience with the technology. Given the overwhelming degree to which technology surrounds and mediates modern life, students are possibly more likely to have prior experience with a particular technological device than a comparable example of the scientific principle from the natural world.

While technology created by people adheres to all of the physical principles governing the natural world, an understanding of the physical science principles at work in some aspect of technology is a critical component of overall understanding. Explanations of technology that are limited to the scientific principles at work remain an incomplete understanding of technology. In some cases there is one scientific principle or understanding that is particularly important or especially characteristic of a particular technology. In these instances it could be said that understanding the science is equivalent to understanding the technology or how the technology works. However, most technologies utilize a wide range of scientific principles often from diverse fields and the collection of scientific principles at work in a given device rarely form a set that is conceptually coherent from the view of logical elucidation of the science. Engineering and science are distinct activities and the set of examples that best illustrates one is not likely to be the best set of examples illustrating the other. Focusing on one scientific principle at work in a technological device also does not address the system nature that is an essential characteristic of most engineered products. Science-based approaches to understanding technology view technology through the same perspective that the scientific fields view the natural world: as preexisting phenomena to be deciphered. The underlying science principles approach finds it difficult to address the importance of the social context or any other aspects of the decisionmaking process underlying the particular form taken by a technological product. Explaining science principles in the context of technology is primarily about the science and not about the technology. Discussion of technological devices can seem out of context or only partially explained.

\section{How Things Work.}

There are a variety of information sources that aim to explain technology to a general audience. Technology is a major aspect of everyday life and it is not surprising that interested individuals would seek out sources of information or explanations of familiar technologies. A number of 
such information sources characterize themselves as attempting to explain "how things work." Illustrative example include the extensive website "How Stuff Works" ${ }^{11 "}$ and related book ${ }^{12}$, the popular books by David Macaulay "The Way Things Work, ${ }^{13, "}$

Recent website-based explanations of technology are the most recent form of "how things work" explanations of technology that can be seen stretching back from the present into the technological past. A variety of other popular "how things work" materials can be found from the past decades ${ }^{14,15}$. Some of these are survey or encyclopedic in scope, others focus on a small range of technological devices or products ${ }^{16}$.

These works can be characterized by a similar approach to explaining technology. They are intended for a general, curious, audience and assume no prerequisite knowledge of science or mathematics. Explanations rely on verbal descriptions and visual aids and are usually selfcontained, or highly simplified, explanations of relevant science and engineering principles.

Other strengths of "how things work materials" include presenting an overall or complete system view of the technology with a focus on the entire device operation rather than an isolated component. Some present practical relevant information relating to the operation, repair, or maintenance of the technology ${ }^{17}$.

Interestingly these materials explaining technology rely heavily on visual aids. In any particular era they tend to employ the best available means of conveying visual information. In the present this includes video and animation on websites. Prior to this, books printed in high quality color were employed. In the more distant past that was dominated by text-only publications, the "how things work books" were distinguished by extensive use of line drawings and illustrations. Use of the best available printing or communication technology to engage the visual senses of the general audience have served to help captivate the attention of the general public in these explanations of how things work.

While the "how things work" materials are commendable for accessibility to a general audience and use of visual aids, an area of omission can also be cited. A main drawback in aiming to be accessible to a general audience the works are little informed by the methodologies of the engineering disciplines usually responsible for creating, developing and improving these technologies. These works do not rely on prerequisite knowledge of engineering, but they do not lead the reader toward a more sophisticated level of understanding either. There is no link or bridge to the engineering disciplines. In being self-contained, the readers of these materials are also insulated from the possibility of being led to a higher level of understanding of technology such as that required by those actually responsible for creating technology on a day-to-day basis. This insulation protects the general reader from the danger of being overwhelmed by complex discipline specific explanations, vocabulary, or jargon. At the same time it deprives the general reader with the opportunity to gain a more in-depth understanding of the technology that a judicious connection with actual engineering could provide. The "how things work" materials start at a general level but they end there as well. 


\section{Engineering Design Process}

The engineering design process is often cited as the key or unique characteristic of the discipline of engineering ${ }^{18-20}$. The engineering design process is seen as one of the defining traits of engineering. The engineering design process is however an activity considerably distinct and different from the scientific method in that it emphasizes the creation of technology and problem-solving rather than hypothesis testing. This leads to the view that understanding technology means understanding, and being able to carry out, the engineering design process.

Materials are available to introduce non-engineers to the rudiments of the engineering design method. Curricula aimed at technology and engineering for K-12 audiences typically emphasize use of engineering design methods of problem solving ${ }^{21}$. Engineering design is a common theme of introduction to engineering courses for first-year undergraduates as represented by some introduction to engineering textbooks ${ }^{23-25}$.

A strength of focusing on engineering design for either K-12 students, beginning engineering students, or the general public, is that the design process emphasizes the central aspect of engineering and technology which is the creation of physical objects of some type to solve problems or provide for specific needs. Carrying out design projects allows students to be active and engaged. Design activity can utilize a variety of materials from simple to sophisticated. The presentation of the basics of engineering design methodology does not require mathematics or other background knowledge so it is accessible to children or a general audience without prerequisite. Engineering design methods are also readily transposed into problem-solving in areas not strictly technological, and hence can be argued to be an important, relevant, or practical skill that should be in the repertoire of all educated individuals not just those intending to be professional engineers.

However understanding and even being able to use the engineering design process is not sufficient to acquire an understanding of technology and engineering. Engineering design is a unique activity that distinguishes engineering from other professions, however, engineering design is most importantly a process used to develop new technology. Engineering design professionals create new technology using the design process or methodology. Understanding the engineering design process does not necessarily explain, or is not necessarily the most appropriate way, to understand engineering products. To understand engineering one must understand the design process but the design process disappears once the artifacts are created.

Another problem with exclusive focus on the design process is that the engineering design process must utilize and integrate new technology with the plethora of already existing technology. In understanding engineering and technology, the design process affords little guidance on grappling with the actual items from which engineering designs must be created. This is a particular issue with beginning engineering students. It is difficult to carry out a meaningful design without an understanding of the elements from which that design is composed. 


\section{Need for a Definition of Engineering Thinking}

The effort to promote the broader understanding of technology by non-engineers would be aided by establishment of a consistent framework or approach to understanding the wide variety of technical products developed and used by people. This framework should be a uniquely engineering way of thinking. Engineering is the profession with the primary task of creating new technology. Therefore, engineering must use some ways of thinking that are unique to the discipline. An answer is needed to the question: "How do engineers think about technology or what is engineering thinking?"

A key step in promoting a broader understanding of technology is to establish the meaning of using engineering thinking to understand how things work. Engineering thinking should provide a framework or approach to understanding the wide variety of technical products developed and used by people. The intent is to make it possible to understand technology by thinking like an engineer. A key step is to explain an engineering way of thinking. Non-engineers should not just understand engineering, but understand engineering thinking.

A framework or organizational principle is needed so that the non-engineering audience can develop knowledge of some key ideas of engineering that contribute to the development of technological products. This knowledge should not be device-specific. The framework should provide knowledge that is transferrable or applicable to understanding any technology.

\section{Functional Analysis Organizational Framework}

The technique of functional analysis or functional decomposition used in engineering design and systems engineering can be adapted to serve as an organizational framework for describing the operation of technological devices. Functional analysis can be used in describing and understanding technology and is independent of the technology itself.

Functional analysis is most often employed in the context of engineering product development ${ }^{26,27}$ and systems engineering ${ }^{28-30}$. The methods of functional analysis developed for this context are directed toward an end goal of creating new technological devices and systems. However, as shown in the following sections, functional analysis can be used as a framework or way of thinking that can be used to understand existing technology.

\section{Engineering Thinking is Thinking Functionally}

The adaptation of functional analysis to explain how technology works, establishes that a key idea of engineering is thinking functionally about the world. Engineering thinking is thinking functionally. Understanding functional analysis and thinking functionally are synonymous with understanding both the engineering process and the technological products of engineering

The idea that engineering thinking is thinking in terms of function is supported by examples from engineering disciplines at the diverse ends of the spectrum of technical products. Both product development and systems engineering utilize functional analysis as a central technique. Product development is oriented toward development and improvement of new and existing technological devices. Product development efforts employ functional analysis as a perspective 
and technique in the design process ${ }^{26}$. The focus is often on products utilized by the individual mass-market consumer ${ }^{27}$.

At the other end of the technology spectrum, systems engineering emphasizes developing and managing extremely complex technological products such as defense systems that can be large in extent in both space and time. Functional analysis is a primary tool in systems engineering design in the form of the functional flow block diagram ${ }^{28-30}$. In systems engineering applications the same basic functional analysis ideas are applied to develop technology vastly beyond the scale of that used by the individual consumer.

Each of the major engineering disciplines can also be seen as employing a form of functional thinking in the development of particular classes or domains of technological products. For example, mechanical engineering machine design addresses components such as gears, cams, and bearings each of which provide a specific functions in a particular class of technological products $^{31}$. In chemical engineering, the concepts of unit operations and unit processes form functional elements used in developing material transformation processes ${ }^{32}$. Electrical engineering is based on specific components which provide well-defined functions providing specific capabilities utilized in differing specific circuit applications. Similarly the diverse products of civil engineering utilize the functional design elements characteristic of civil infrastructure ${ }^{33}$.

Since functional thinking is used in the development of technology, it should also be possible to adapt its basic principles to serve as a framework for explaining engineered or human-built products.

\section{Outline of Functional Analysis Principles}

Functional analysis uses block-diagram type of structure to represent a technical system. In functional analysis or functional decomposition a product is represented as a functional system $^{26,34}$.The "black box" function transforms input into outputs. Figure 1 illustrates the basic functional analysis representation.

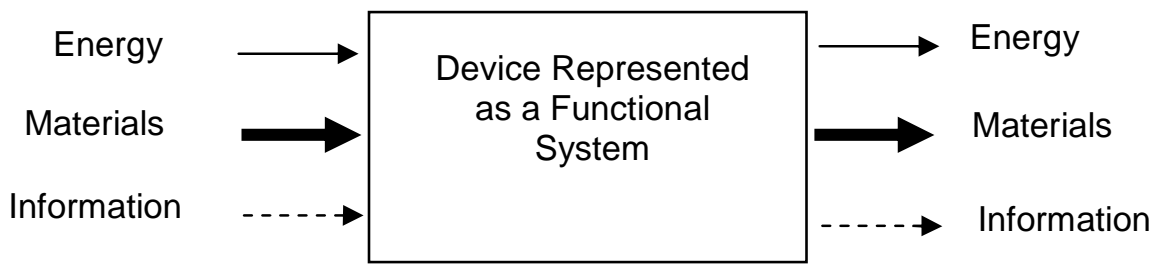

Figure 1: Basic Functional Analysis Representation.

The overall function of a device must be divided into recognizable subtasks often termed subfunctions. Functions are expressed using verb-noun pairs. Verbs must be active verbs. Examples might be actuate-electricity or transmit-torque. Some physical entity is associated 
with each subfunction. An illustration of a hypothetical device subfunction structure is shown in Figure 2.

Figure 3 shows the functional analysis representation of a hair dryer. The hair dryer is considered to be the system under consideration. Material in the form of air enters the system along with energy through electric current which enters the system via the cord. The electric motor provides the function of converting electric current into torque which rotates a fan. The fan pressurizes the air creating flow over the heating coils. The electric heater transforms electric current into sensible heat which is transferred to the air. The heated air is an output of the device along with information in the form of noise which indicated the dryer is operating as does the temperature of the output air stream. Some heat is also transferred to the dryer housing.

A strength of the functional analysis representation is the clear illustration that engineered products utilize a number of pre-existing components that provide specific subfunctions in the overall operation of the device. In the hair dryer major components include the cord, switch, the electric motor, the fan blades and the heater. The components provide specific functions which can also be utilized in other devices to carry out similar functions. In this way the non-engineer or even the novice engineer can begin to develop a working vocabulary of specific devices that provide useful functions. These components can be described in terms of the underlying scientific principles of their operation and the mathematical expressions that describe their performance.

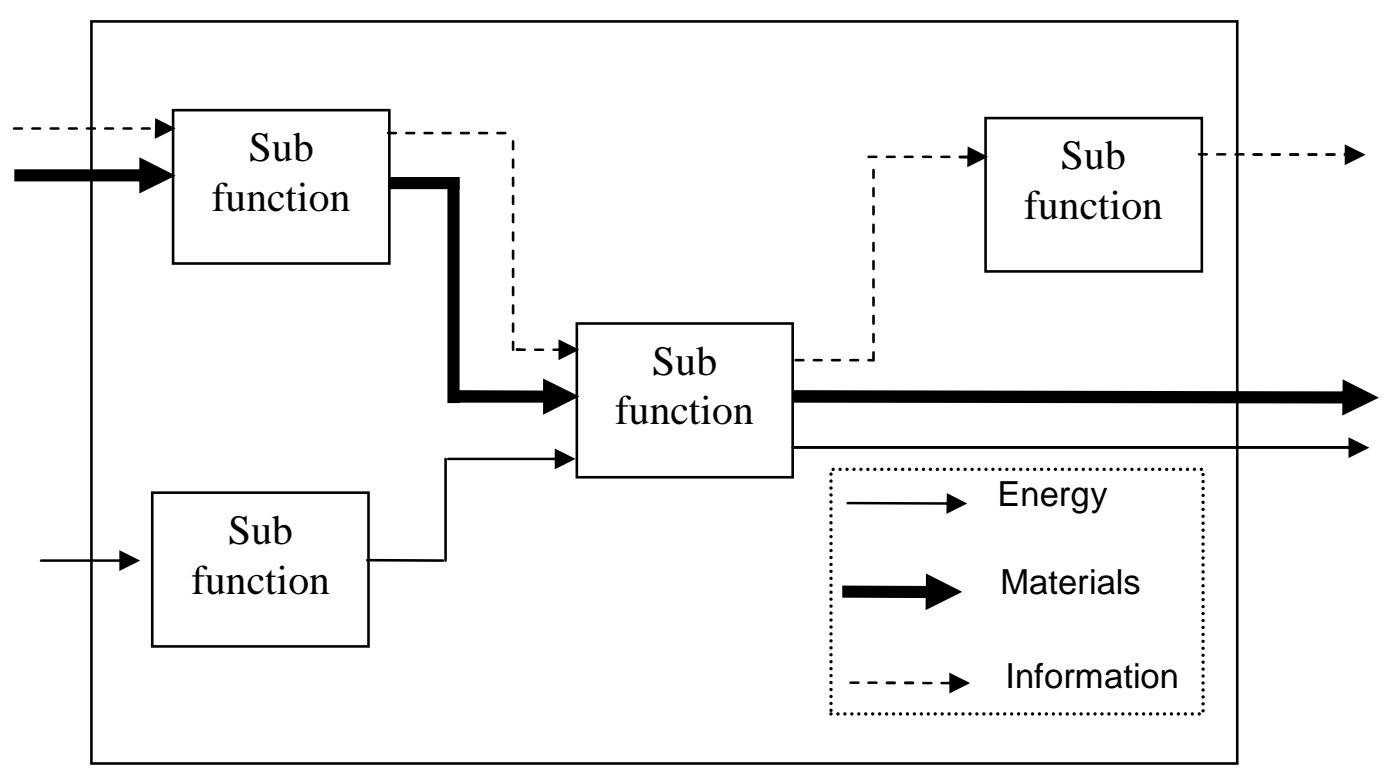

Figure 2: Illustration of a Hypothetical Device Subfunction Structure. 


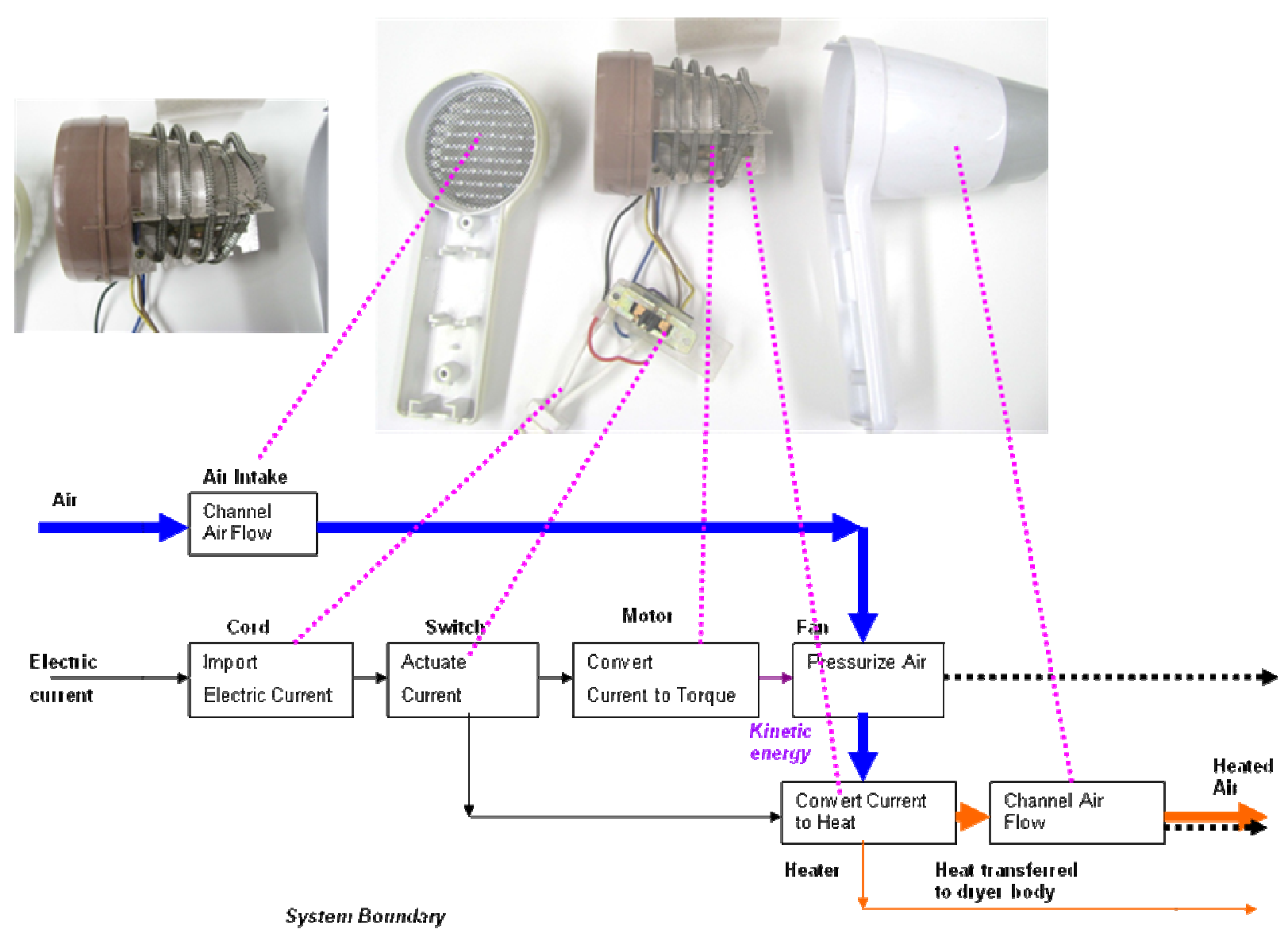

Figure 3: Functional Analysis Description of a Hair Dryer

\section{Benefits of Functional Thinking}

In using functional analysis, or functional thinking, as a framework or method to describe how things work from an engineering perspective, a number of benefits are realized. These can be summarized as:

1. The method reflects an approach or method of understanding technology that is characteristic of engineering.

2. It is possible to include relevant scientific principles and the use of mathematics in applications that reflect modern engineering practice.

3. Incorporates a systems perspective in describing technology.

4. Is able to be used to describe the products of any of the engineering disciplines.

Functional thinking is not exclusive to one field. It is a general engineering approach. 
5. When used to describe engineering to a general audience, elaborate prerequisite knowledge is not needed to understand the approach. It is a largely self-contained framework that would be accessible to any college student.

6. The method is consistent with and merges naturally into the engineering design process.

7. The framework can be used to describe any technological product that is the outcome of the engineering process. It is flexible in describing the size, scale, extent or complexity of the product.

8. This approach is something that all engineers would be able to understand and could be taught by faculty from any engineering discipline.

9. The method or framework is reflective of the processes actually used by practicing engineers in viewing the products or their work. It reflects how engineers think about human-made artifacts.

10. Functional analysis is not a static technique but can be applied to the constantly changing nature of technology. Description of the evolving state-of-the-art should be accessible with this framework.

\section{Current and Future Work}

Current work includes an effort to utilize functional analysis and functional thinking in both a course for non-engineering students and an introduction to engineering course for prospective engineers $^{35}$. An important step is developing an explanation of functional analysis that is accessible to anyone without prerequisite background technical knowledge. Functional analysis was originally developed as a design technique. It is therefore necessary to modify or adapt this design method for use in understanding technology. However this is not taking functional analysis far from its usual application, since in developing new technology in the design setting, this technique is used for understanding problems and expressing the elements of a solution in functional form.

\section{Conclusions}

Functional analysis provides a framework for a "how things work" approach rooted in a major technique of engineering design methodology. This produces several benefits for engineering education. Introduction to engineering courses often emphasize the design process as a defining characteristic of engineering. While this is accurate, most engineering designs must be produced from physical objects. A frequent complaint of engineering instructors is a lack of awareness on the part of the students of the actual physical components from which designs might be realized and the procedures and techniques for their utilization. Functional analysis emphasizes the role of subfunctions which may be manipulated, modified and adapted to a particular design problem. Important devices such as the electric motor can be introduced to novice engineers in an engineering context as common subfunctions. Additionally, innovation in product design is 
frequently achieved through improving existing or creating new subfunctions. Innovation can be merged naturally with engineering education using the structure and vocabulary provided by functional analysis.

\section{Acknowledgement}

The work was supported by the National Science Foundation under award: DUE-0633277. Any opinions, findings, and conclusions or recommendations expressed in this material are those of the authors and do not necessarily reflect the views of the National Science Foundation. A portion of this work was carried out while the author was serving as a CASEE Senior Fellow.

\section{Bibliography}

1. Committee on Public Understanding of Engineering Messages, Changing the Conversation: Messages for Improving Public Understanding of Engineering, National Academy of Engineering, National Academies Press, (2008).

2. Technically speaking: Why all Americans need to know more about technology, Greg Pearson and A. Thomas Young, editors, National Academies Press, (2002).

3. Tech Tally: Approaches to Assessing Technological Literacy, Elsa Garmire and Greg Pearson, editors, National Academies Press, (2006).

4. Bloomfield, L., How Things Work: The Physics of Everyday Life, 3rd Edition, Wiley, New York, (2006).

5. Dudley, J. M., and Bold, G. E. J, Top-down teaching in noncalculus-based introductory physics classes, American Journal of Physics, vol 64 (1996) 418.

6. Watson, G., Silicon, Circuits, and the Digital Revolution, The University of Delaware, <http://www.physics.udel.edu/ watson/scen103/colloq2000/main.html> (accessed February, 1, 2009).

7. Wilson, Jerry D., Physics: A Practical and Conceptual Approach, Saunders College Publishing, Fort Worth, (1993).

8. Trefil, James, and Robert M. Hazen, The Sciences: An Integrated Approach, Wiley, New York, (1995).

9. Hewitt, Paul G., Conceptual Physics, $10^{\text {th }}$ Edition, Pearson Addison Wesley, San Francisco, (2006).

10. Bransford, J.D., A.L. Brown, and R.R. Cocking, (Editors). How People Learn: Brain, Mind, Experience, and School, National Academy Press, (1999).

11. How Stuff Works, http://www.howstuffworks.com/, One Capital City Plaza, 3350 Peachtree Road, Atlanta, GA. (accessed February 1, 2009).

12. Brain, Marshall, Editor, "How Stuff Works", Hungry Minds, New York, New York, (2001).

13. Macaulay, David, The NEW Way Things Work, Houghton Mifflin Company, Boston, (1998).

14. Constable, George, Editor, How Things Work, Series, Time-Life Books, (1990).

15. The Way Things Work: An Illustrated Encyclopedia of Technology, Simon and Schuster, New York, New York (1967). 
16. White, Ron, “How Computers Work," Ziff-Davis Press, Emeryville, California (1993).

17. Porter, John Paul, Editor, How Things Work in Your Home (and what to do when they don't), Time-Life Books (1985).

18. Petrosky, Henry, Invention by design: How Engineers Get From Thought to Thing, Harvard University Press, Cambridge, (1996).

19. Adams, James L., Flying Buttresses, Entropy, and O-rings: The world of an engineer, Harvard University Press, Cambridge, (1991).

20. Bucciarelli, Louis L., Designing Engineers, The MIT Press, Cambridge, (1994).

21. American Society for Engineering Education K12 Engineering Center, http://www.engineeringk12.org/, (accessed February 1, 2009).

22. Dhillon, B.S., Engineering Design: A Modern Approach, Irwin, (1996).

23. Voland, Gerard, Engineering by Design, $2^{\text {nd }}$. Prentice Hall, Upper Saddle River, New Jersey (2004).

24. Horenstein, Mark M. Design Concepts for Engineers, $3^{\text {rd }}$, Prentice Hall, Upper Saddle River, New Jersey (2006).

25. Howell, Steven K., Engineering Design and Problem Solving, $2^{\text {nd }}$, Prentice Hall, Upper Saddle River, New Jersey (2002).

26. Otto, Kevin N., and Wood, Kristin L., Product Design: Techniques in Reverse Engineering and New Product Development, Prentice Hall, Upper Saddle River, New Jersey (2001).

27. Ulrich, Karl T., and Steven D. Eppinger, Product Design and Development, $4^{\text {th }}$ Edition, McGraw-Hill, New York, (2008).

28. Systems Engineering Fundamentals, Department of Defense, Systems Management College, Defense Acquisition University Press, January (2001).

29. Shishko, Robert., et al., NASA Systems Engineering Handbook, National Aeronautics and Space Administration, SP-6105, (1995).

30. Oliver, David W., Timothy P. Kelliher, James G. Keegan, Jr. Engineering Complex Systems with Models and Objects, McGraw-Hill, New York (1997).

31. Shigley, Joesph E., Charles R. Mischke, Standard Handbook of Machine Design, $2^{\text {nd }}$ Edition, Mc-Graw Hill, New York, (1996).

32. McCabe, Warren L., Julian C. Smith, Peter Harriott, Unit Operations of Chemical Engineering, $7^{\text {th }}$ Edition, McGraw-Hill (2005).

33. Merritt, Frederick S., M. Kent Loftin, Jonathan T. Ricketts, Standard Handbook for Civil Engineers, $4^{\text {th }}$ Edition, Mc-Graw Hill, New York (1996).

34. Pahl, Gerhard, and Wolfgang Beitz, Engineering Design: A Systematic Approach, Springer-Verlag, (1991).

35. Krupczak, J.J., "Using Insights from Non-engineers to Improve Introduction to Engineering via Functional Analysis," Proceedings of the American Society for Engineering Education Annual Conference, June 23-26, 2007, Honolulu, HI. 